Research Article

\title{
Research into Correlation between the Lubrication Mode of Contact Surfaces and Dynamic Parameters of Turbo-Generator Transmissions
}

\author{
Marek Kočiško $(\mathbb{D})$, Petr Baron $(\mathbb{D}$, Monika Telíšková $(\mathbb{D})$, Jozef Török $(\mathbb{D}$, and Anna Bašistová \\ Faculty of Manufacturing Technologies with a Seat in Presov, Technical University of Košice, Košice, Slovakia \\ Correspondence should be addressed to Petr Baron; petr.baron@tuke.sk
}

Received 6 March 2019; Revised 15 July 2019; Accepted 9 September 2019; Published 9 October 2019

Academic Editor: Stanislaw Dymek

Copyright ( $) 2019$ Marek Kočiško et al. This is an open access article distributed under the Creative Commons Attribution License, which permits unrestricted use, distribution, and reproduction in any medium, provided the original work is properly cited.

\begin{abstract}
The paper presents the results of an experimental study aimed at assessing the correlation between the measurement of dynamic parameters (vibration, high-frequency vibration, and acoustic emission) and the analysis of friction mode and the state of lubrication of the contact surfaces of two gearboxes in the turbo-generator assembly (high-speed single-body steam turbine-gearbox-generator) with the transmission power of no more than $50 \mathrm{MW}$. The analysis confirmed the assumption of a significant correlation of the monitored high-frequency vibration signal with the unsatisfactory engagement of the gear teeth. Through vibration analysis, an increased level of the tooth vibration component and vibration multiples with increased acoustic emission were identified in gearbox operation. The gear oil of one of the gearboxes examined showed a loss of additive elements in the real operation of the contact surfaces of the teeth engagement. The trend analysis confirmed the complexity of the monitored transmission operation in terms of the friction mode and the influence of the oil quality on the state of the tooth flank microgeometry.
\end{abstract}

\section{Introduction}

Nowadays, industries are based on a wide use of machinery and enginery without which production would not be possible. Therefore, the demands on production, growth, and quality, which are very closely related to the demands on the reliability of the production equipment, are constantly being laid down. Regular inspection of the technical condition and early diagnostics of an error in many cases lead to the early detection of a malfunction that could cause considerable damage during operation. Technical diagnostics is of major importance for the operation and maintenance of equipment [1]. It is a subject of wide interest not only in the scientific field but also in the field of application of its results in the area of newly developed methods and their use in professional practice.

The aim of monitoring the rotating machine vibration is to obtain data about its technical condition. The process data obtained in this way comprise an information base for identification of faults and errors in the technical system and consequently the provision of timely repair or maintenance, in order to extend the service life and reliability of individual machine parts and equipment as a whole. During its operation, the technical equipment generates vibrations which, on the one hand, represent possible damage to the machine node and also reflects the real operating conditions of the machine. Vibrations are considered to be the best operating parameter by which low-frequency dynamic states can be assessed, such as imbalance, loss of alignment, mechanical backlash of the housing, overrun of the stability of flexible rotor systems, insufficiently rigid foundations, bent shaft, excessive bearing wear, or the fact that a rotor blade has broken loose [2]. The basic principle of individual methods of vibrodiagnostics is based on the measurement of the characteristic values of mechanical vibration and in the subsequent comparison of its results with the limit values prescribed by technical standards and the manufacturer, or used on the basis of long-term experience in monitoring the 
technical condition of the equipment. Further evaluation of the vibration signals is based mainly on the analysis of two components, namely, the amplitude and the frequency. Frequency spectrum is also analyzed by the application of multiple methods and indicators such as peak values, peak to peak, mean values, effective values (RMS), time courses, fastFourier transform (FFT), envelope methods, and trending analysis [3].

To determine the bearing lubrication condition, verification of the gearing and lubrication condition in the gearboxes and vibration acceleration measurements can be successfully applied to appropriately selected frequency ranges.

\section{Literature Review}

Generally, the gears represent mechanisms used to transmit power through a rotating motion. There is a change in the torque and speed of the machine. Toothed mechanical gears are tied gears that transmit torque to short distances between the drive and the driven shaft. They work with high efficiency and are quite stable over a large speed range. The gears are a significant source of vibration in the gearboxes. As a result of the load (engagement of the teeth), the toothed gears roll off each other and their contact is accompanied by elastic deformations. Consequently, deviations from the theoretical tooth profile itself can occur, resulting in a transmission error and its subsequent excessive vibration. The emergence of vibrations in gears can also be affected by so-called pitting (occurs by shear and pressure acting on the flanks in the toothing, when various defects appear on the surface as a result of cyclic loading), bearing defects, shafts oscillation, and so on. It is important to note that working condition of gear system is extremely complex. Typically, the primary engine introduces an external load; however, internal incentives introduced by time-varying meshing stiffness and gear error are the main source of vibration in the transmission system. Lu et al. in their published work [4] describe the novelty of the integral squeeze film damper (ISFD), which is proposed to reduce the vibration excitation of the gear system through the foundation. Four ISFD designs were tested experimentally with an open first-grade spur gear system. Different vibration amplitudes of gear shafts with ISFD installed on driven or driving shafts were compared. Results showing that vibration reduction is better when ISFD is installed on the drive shaft than on the driving shaft [4]. ISFD elastic damping support can effectively reduce transmission of meshing excitation effectively. No additional changes need to be made to the equipment and foundation to achieve good vibration control [4]. Fargère and Velex in their scientific article "Some Experimental and Simulation Results on the Dynamic Behavior of Spur and Helical Geared Transmissions with Journal Bearings" describe research on the interactions between dynamic and tribological behavior of gears [5]. A model is introduced which incorporates most of the possible interactions between gears, shafts, and hydrodynamic journal bearings. It combines a specific element for wide-faced gears that includes normal contact conditions between actual mating teeth, that is, with tooth shape deviations and mounting errors, by journal bearings determined by solving Reynolds' equation [5]. The authors compared the results of the simulation with the measured data obtained on a high-precision test equipment. The authors present the model, which is the global behavior of the system (shaft vibrations) and the contacts between the gear teeth and those in the journal bearings. Tooth microgeometry including shape modifications and errors is taken into account, and the influence of temperature on the properties of the bearing lubricant is also considered. In their paper "Feature Extraction Using Discrete Wavelet Transform for Gear Fault Diagnosis of Wind Turbine Gearbox," [5] Bajric et al. characterize vibration diagnostics as one of the most common methods for assessing the condition of a wind turbine equipped with a gearbox [6]. Due to the stochastic operation of wind turbines, the gearbox shaft rotating speed changes with high percentage, which is the application of traditional vibration signal processing techniques, such as fast-Fourier transform [6]. This work presents a new approach to high-speed wind turbine shafts diagnostics using discrete wavelet transform and timesynchronous averaging [6]. One of the most important insights to be drawn from this work is choosing a suitable reference for a synchronous averaging and condition indicator that can lead to the earlier diagnosis of wind turbine high-speed shaft gear fault.

The aim of the scientific paper by Barbieri et al. was to identify the presence of component errors in car transmissions by comparing the vibration signals of damaged and undamaged transmissions. Different signal analysis techniques based on wavelet transform, mathematical morphology, and energy (entropy) were used to verify the presence of damage in the systems [7]. A signal processing technique combining pattern spectrum and selective filtering in certain frequencies ranges was used for identification of component failures [7].

An interesting sophisticated solution applied to the process of identifying and classifying faults in transmissions is the implementation of the convolutional neural network deep learning algorithm (CNN). It is a network of small computing units, the so-called neurons, that send processed information to each other down a hierarchy. Chen et al. have published research results in which various combinations of fault conditions have been integrated within the neural network. The present CNN method identifies and classifies faults in gearbox using vibration signals measured with an accelerometer. Feature representations are selected with the input parameters of the CNN with the vector formed by RMS values, standard deviation, skewness, kurtosis, rotation frequency, and applied load. For the evaluation of the proposed CNN method, the gearbox fault diagnosis experiments were carried out using different techniques. The results show that the present method has outstanding performance of gearbox fault diagnosis, compared with peer methods [8]. Strączkiewicz and Barszcz their paper "Application of Artificial Neural Network for Damage Detection in the Planetary Gearbox of Wind Turbine," used the neural network to identify wind turbine transmission failures. The sudden increase in the monitored signal does not 
automatically translate into an error. To overcome this obstacle, it is proposed to detect and fault with the artificial neural network (ANN), and further observation of linear regression parameters was calculated on the estimation error between healthy and unknown condition. The proposed reasoning is presented on the real-life example of a ring gear fault in a wind turbine's planetary gearbox [9].

In their publication, Myshkin and Marková discuss the trends in tribodiagnostics, the development of continuous monitoring systems and the increase in the number of sensors in the oil line, software development, including artificial intelligence methods, and the reduction of tribodiagnosis costs [10]. It has been demonstrated that the most promising direction in the performance of the oil taking into account the existing ambiguity, incompleteness, and fuzziness of information is the application of an expert system [11]. In their publication, "Early Fault Diagnostics of Bearing and Stator Faults of Single-Phase Induction Motor Using Acoustic Signals," Glowacz et al. are concerned with earlyfault diagnostics based on acoustic signals for single-phase induction motor. The authors have measured and analyzed the conditions of single-phase induction motor and engine of single-phase induction motor with wrong bearing [11]. Determination of the technical condition of axle housing in a vehicle by means of vibrodiagnostics is discussed in the publication by Furch et al., who describe an experiment in which the vibrations of the axles located in the vehicle axle housing were measured, and the analysis of the measured data was then performed. Subsequently, they analyzed the lubricant samples used for the lubrication of the tested rolling element bearings [12]. Properly chosen technical diagnostics and follow-up measures based on the knowledge of the real condition of the machinery are the main steps that lead to its increased operational ability. Repair costs are often outweighed by investments made in preventive maintenance, as discussed by Glos in "Tribologic Methods Used for Engine Diagnostics" [13]. At present, automated control systems and dilution are assured by complex technical devices that include a large number of elements and have a complex structure. Automated system of management of technical process (ASMTP) is a group of solutions of hardware and software designed for automation control of technological equipment in industrial enterprises. This research is addressed in [14].

Vibrations are a phenomenon accompanying the operation of technical systems. Vibrations characteristics of individual devices operation are unique to a particular device. Connections between the individual functional parts of a technical equipment change during operation. Bearing backlash increases, weight of worn parts changes, operating parameters change [15]. This causes a change in machine vibration. This change is the characteristic of the device and offers information about the states that occurred in the machine structure. Thus, vibration examination and analysis must be an integral part of all activities ensuring optimal operational reliability.

Vibration-based monitoring techniques have been used for detection and diagnosis of defects for several decades. These methods have been traditionally applied, separately in time and frequency domains. A time-domain analysis is based on statistical characteristics of vibration signal such as peak level, standard deviation, skewness, kurtosis, and crest factor. A frequency domain approach uses Fourier methods to transform the time-domain signal to the frequency domain, where further analysis is carried out, conventionally using vibration amplitude and power spectra [15].

\section{Measurement and Analysis of the Turbo Generators' Operating Conditions Based on Technical Diagnostic Methods}

Under the current conditions, the service life of the gear unit toothing is 8 to 10 years. Toothing replacement significantly increases maintenance costs, as the cost of toothing replacement is relatively high. The most important faults detected in the cogwheels are those due to fatigue. Contact fatigue damage is characterized by accumulation of defects in the surface layer of the material if it is subject to excessive cyclic loading of the bodies at their mutual contact point. Figure 1 is a demonstration of gear toothing damage.

The delivery date for a new gear assembly including toothing is 9 to 18 months. In the case of toothing damage, it is necessary to carry out emergency repair and then dynamic rotor balancing. Once repaired, it is possible to operate such a machine at reduced power, max. 50\% of the nominal power.

Figure 2 shows an example of emergency repair of the cogwheel by welding, its reassembly, and commissioning, with a limitation of up to $50 \%$ of the transmitted power.

3.1. The Research Issue. Following the request of our partner, we conducted an analysis of the current state of the turbogenerator gearbox. Our partner uses a three-phase, aircooled synchronous generator to produce electricity. The steam turbine is connected to the generator via a high-speed gearbox ensuring efficient and high-efficiency transmission of torque from the turbine shaft through the clutch to the generator shaft. The turbine and the generator are mounted on a common frame fitted onto a simple reinforced concrete block, separated from the surrounding floor of the machine room to allow for dilatation. The turbo-generator gearbox reduces the speed of the turbine rotor. The reason for the measurements and analyses was an increased noise level of the gearbox. By analyzing the operating parameters, no dependence relationship between the change in the generated noise and the performance, for example, has been detected. Threefold and greater increase in the noise was recorded from the levels of vibration acceleration values through sensors that were placed on the gearbox.

In our laboratory, measurements and subsequent analyzes of turbo generator were conducted focusing on transmission of $50 \mathrm{MW}$ by toothed gear. In order to determine the correlation between the monitored dynamic parameters and the assessment of the friction mode and the lubrication status for the gearbox, the analyzed chemical and physical properties of the oil filling of the examined gearbox 


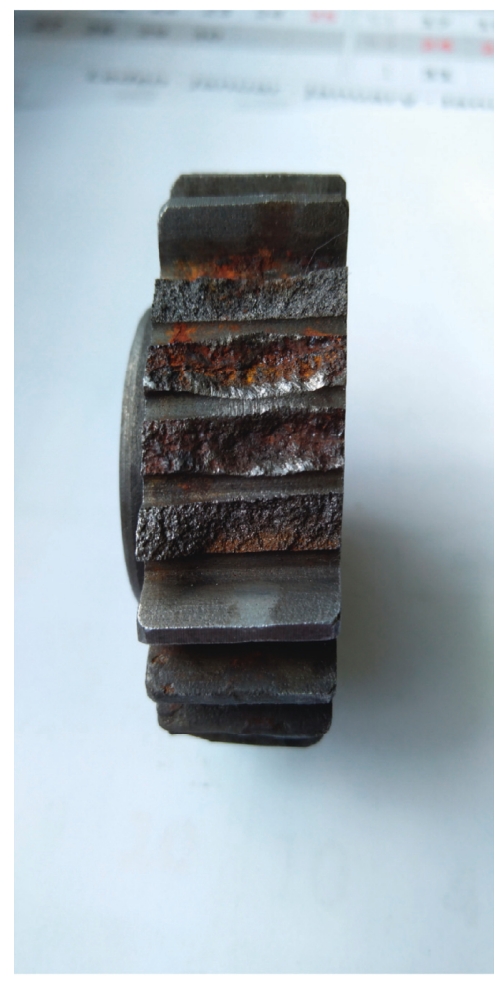

(a)

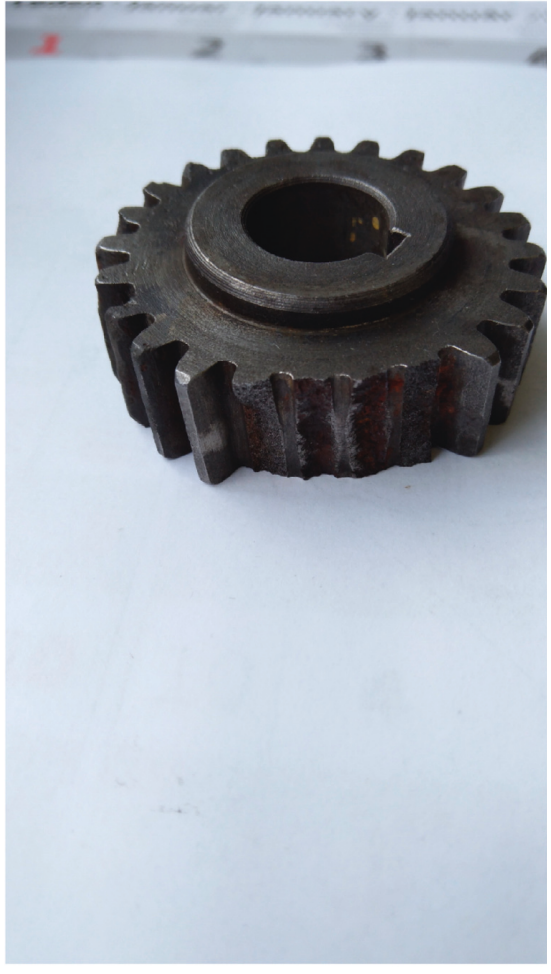

(b)

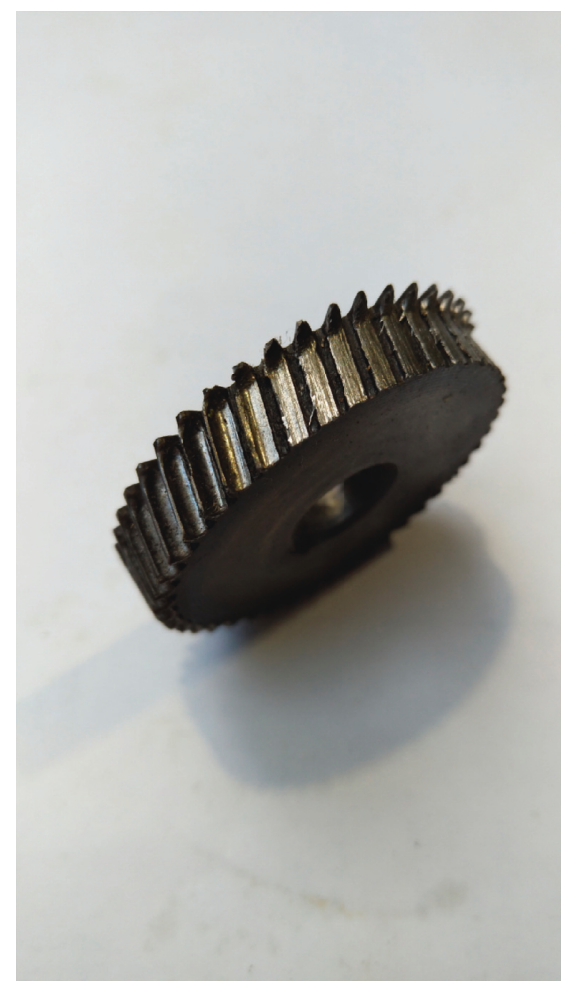

(c)

Figure 1: Demonstration of gear toothing damage.

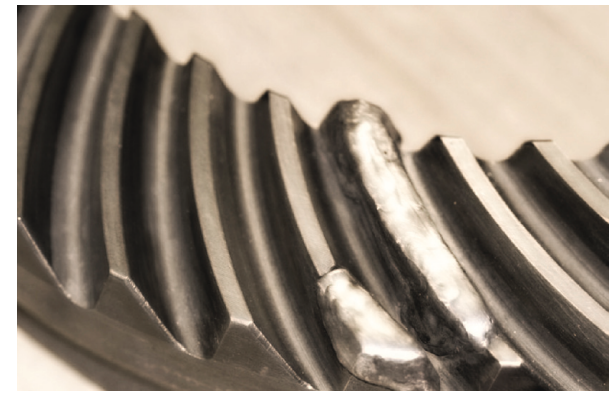

FIGURE 2: Example of emergency repair of the cogwheel by welding.

were compared with the gearbox of the identical turbogenerator system.

On the basis of diagnostics, the following tests and analyzes were performed:

(i) Vibrodiagnostics of the gear unit

(ii) Dynamic signal analysis

(iii) Analysis of lubricating oils with emphasis on lubricity test and load bearing capacity of oil film

The gear unit was used for the transmission of power in the following turbo-generator assembly: high-speed singlestage steam turbine-gear unit-generator. Such a machine design is mainly used in heating plants with power outputs up to $50 \mathrm{MW}$. The basic conditions for using such an assembly in terms of durability and reliability of machine operation include, in particular, the following: (i) The mechanical efficiency of the gear unit and the loss of power transmission are particularly true in the summer when the machine is used for 50\% (no heating period, and only hot water is heated). The overall machine efficiency is less favorable in this type of operation.

(ii) Coaxial alignment of the complete set, bearing in mind that the bearings are located in sliding hydrodynamic bearings-displacement of the pin axis during operation and during shutdown. At the same time, the sprocket of the gearbox works due to the forces at the top of the bearing. It is necessary to calculate these displacements and correct the setting in both the horizontal and the vertical directions.

(iii) Coaxial shaft alignment is also required when considering thermal expansion during operations. It is recommended to determine the temperature ratios during operation and calculate the correction based on the real conditions of temperature ratios at individual positions (aggregates).

(iv) Diagnostic methods for the monitoring of machinery condition, permanent online measurements of selected parameters, especially temperature, vibration in the meaning of ISO, high-frequency vibrations and acoustic emission, and lubricant monitoring from the point of view of the friction mode. 
3.2. Materials and Methods. Vibrodiagnostic measurement is a non-disassembly and nondestructive diagnostics of rotary machines, which allows a consistent assessment of the machine's technical condition even without shutting down the machine. The measurement was aimed at assessing the operational status of two turbo generators with different oil fillings using the technical diagnostics methods. There are two ways to implement diagnostic methods, depending on whether the object being diagnosed is out of operation-offline, or in operation-online.

To assess vibration in the low-frequency area, the following were used:

(i) Velocity method (vibration speed), unit mm/s, RMS detection

(ii) In accordance with ISO10816-3: 2009, FFT (fastFourier transform) spectrum for the $10-800 \mathrm{~Hz}$ frequency range

(iii) Enveloping acceleration, Eg, PtP detection, 50$1000 \mathrm{~Hz}$ frequency range, FFT spectrum, and time recording

To assess vibration in the high-frequency area, the following were used:

(i) Acceleration measurement method (vibration acceleration), unit g, PtP detection, Frequency range up to $20 \mathrm{kHz}$, FFT spectrum, and time recording.

(ii) Enveloping acceleration method, Eg, PtP detection, frequency range up to $10 \mathrm{kHz}$ and up to $20 \mathrm{kHz}$, FFT spectrum, and time recording.

(iii) A detailed vibration analysis to assess the condition of the gear unit toothing and rotors:

(a) Frequency spectrum analysis and vector of important frequency components (amplitude and rotational frequency phase)

(b) Toothing components of vibrations and their harmonic multiples, relative shaft vibration analysis, and an analysis of a shaft center position

The following devices were used for the diagnostic measurement of vibration (data collection) and analysis:

(i) MicrologGX frequency analyzer and data collector

(ii) AptitudeAnalyst SW environment

(iii) The manufacturer of SKF Condition Monitoring machinery (USA)

(iv) Vibration sensor, Wilcoxon Research Accelerometer, SKF786M model, sensitivity $100 \mathrm{mV} / \mathrm{g}$, and frequency range $1-20,000 \mathrm{~Hz}$

\subsubsection{Method of Cyclic Time-Averaging (CTA)}

(i) The advanced analysis of the condition of the toothing

(ii) A detailed vibration analysis to assess the condition of the toothing and gear rotors, in particular, frequency spectrum analysis, vector of important frequency components (in particular amplitude and rotational frequency phase), toothing components of vibrations and their harmonic multiples, relative shaft vibration analysis, and an analysis of a shaft center position

\subsubsection{Lubricating Oil Analyses}

(i) The kinematic viscosity of the oil as a proportion of the dynamic viscosity and density of the fluid

(ii) Water content

(iii) Analysis of elements of additives concentration

(iv) Reichert lubricity test

(v) FTIR spectra

\section{Experiments and Measurement Results}

Figure 3 shows continuous online monitoring of selected operating parameters for 24 hours. The black color indicates the trend of high-frequency absolute vibrations up to $20 \mathrm{kHz}$ for detecting and assessing the gear teeth engagement.

4.1. Frequency Analysis of Signal: High-Frequency Area. The waterfall graph of the frequency spectra in Figure 4 displays the dynamic signal area within high-frequency area of absolute vibrations (acceleration up to $20 \mathrm{kHz}$ ). Dominant frequency components correspond to the gear teeth engagement frequency and harmonic multiples + sidebands.

4.2. CTA Analysis and Graph of Sprocket Vibration Profile. Figure 5(a) displays the calculated vibration profile for quiet gear operation without high amplitudes on the gear teeth engagement frequency. Figure 5(b) shows the analysis of the signal from unstable operation. It is obvious that the gear teeth engagement during instability is markedly deteriorated. This has a direct effect on the rapid wear of the toothing contact surfaces and thus the change in microgeometry. Early toothing failure (fatigue damage and pitting) can also occur with the increase of slip at the expense of the slew.

4.3. Assessment of the Lubricant Condition. Two identical sets of turbo generators TG3 and TG4 were in operation with the usage of gear unit. The analysis of unstable high-frequency vibrations was performed on a TG4 machine where this unfavorable phenomenon occurs. On the TG3 machine, such symptoms of occasional significant deterioration of gear teeth engagement were not detected. Gear units do not have the same oil content. In both cases, ISO VG $46 \mathrm{ki}-$ nematic viscosity turbine oil was used, but the additive concentration and EP and WP properties of the oils were different. Therefore, a lubricant analysis was carried out. The following part of the paper presents the differences found by analyzing the chemical and physical properties of the TG3 and TG4 operating lubricating oils. 


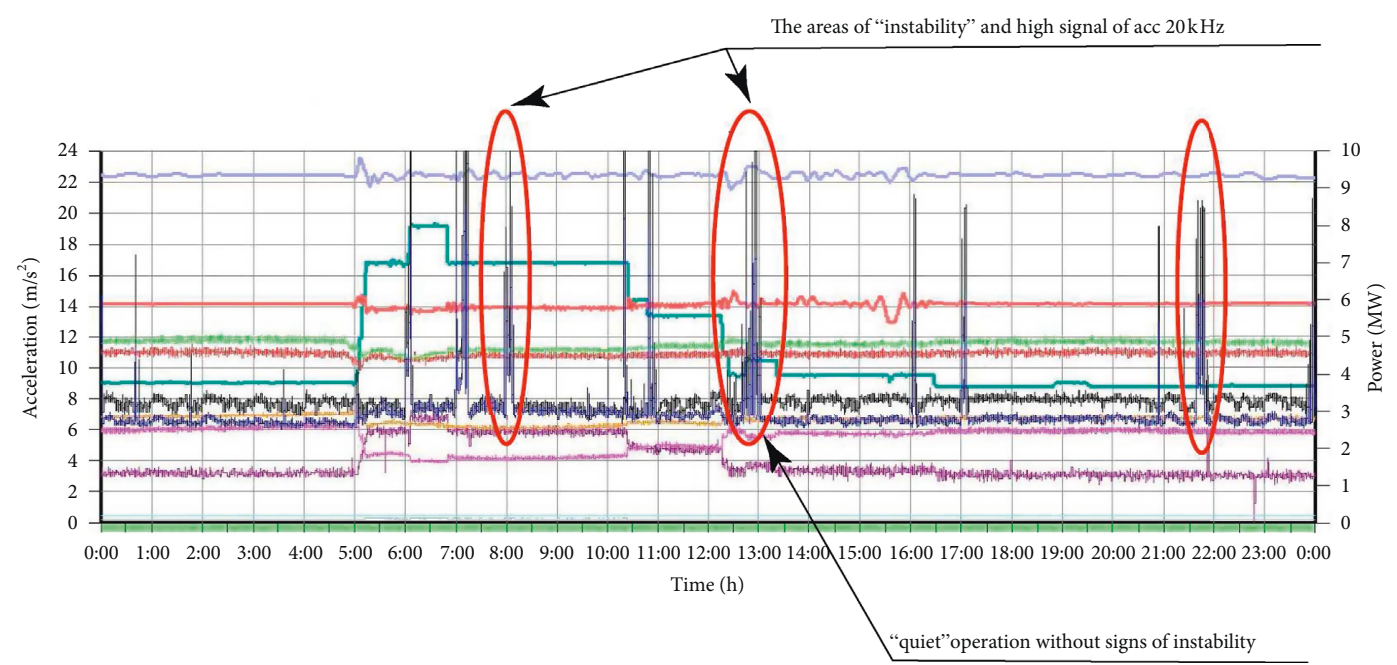

FIgURE 3: The areas of "instability" and high signal of acc $20 \mathrm{kHz}$ and "quiet” operation without signs of instability.

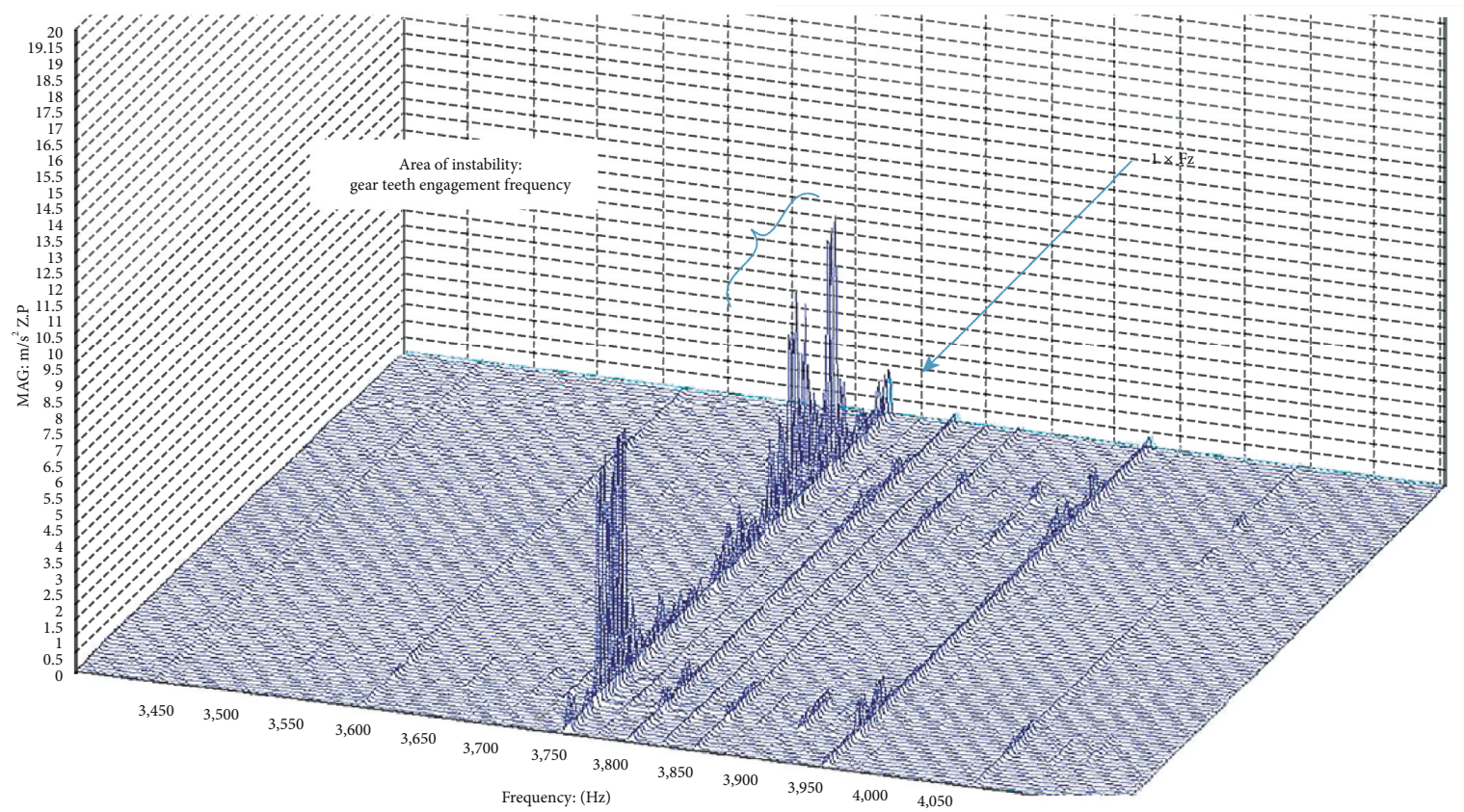

FIgURe 4: Dynamic signal area in the high-frequency acceleration range up to $20 \mathrm{kHz}$.

The kinematic viscosity is the same for both oil fillings (Table 1); diffusion is in line with the recommendations for safe operation of the machine in terms of friction mode.

The water content is increased in both cases (Table 1), slightly above the recommended limit. This phenomenon could be assumed because of the fact that it is a turbo generator, the operating medium of which is hot steam. Increased water content is an accompanying feature of the operation of these machines. Turbine oils are doped with the emphasis on ensuring high oil resistance even when operating with increased water content.

4.4. Concentration of Additives. Table 2 shows a significant difference in the concentration of typical additive elements (P, phosphorus; S, sulphur) in favor of the TG3 filling.
Additives determine lubricating EP and WP properties of oil (when defining lubricating oils, new lubricant properties are often required, such as reduced wear in border lubrication mode-WP additives; high pressure and impact load resistance-EP additives; and good anticorrosion and antifoaming properties) during operation, especially at high speeds and contact pressures in oil film (toothing).

It is important to balance the additives to achieve the optimum performance and stability of lubricating oils.

4.5. Reichert Lubricity Test. Table 3 lists the results of the Reichert test for both oil types examined. The test is designed to determine the point of formation of a lubricating film between two test surfaces. The test starts as a sliding contact between the surfaces and progresses to being hydrodynamically lubricated 


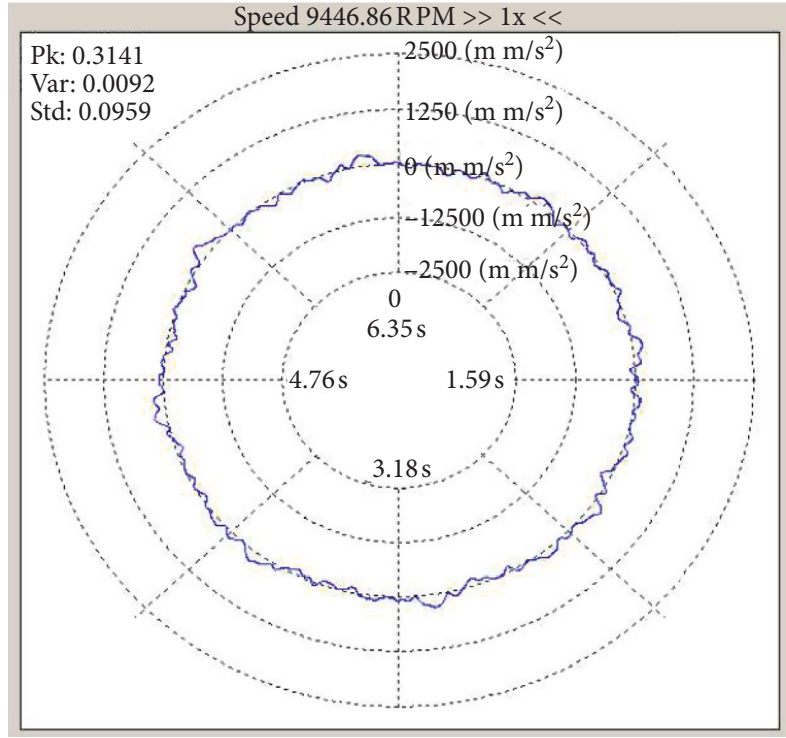

(a)

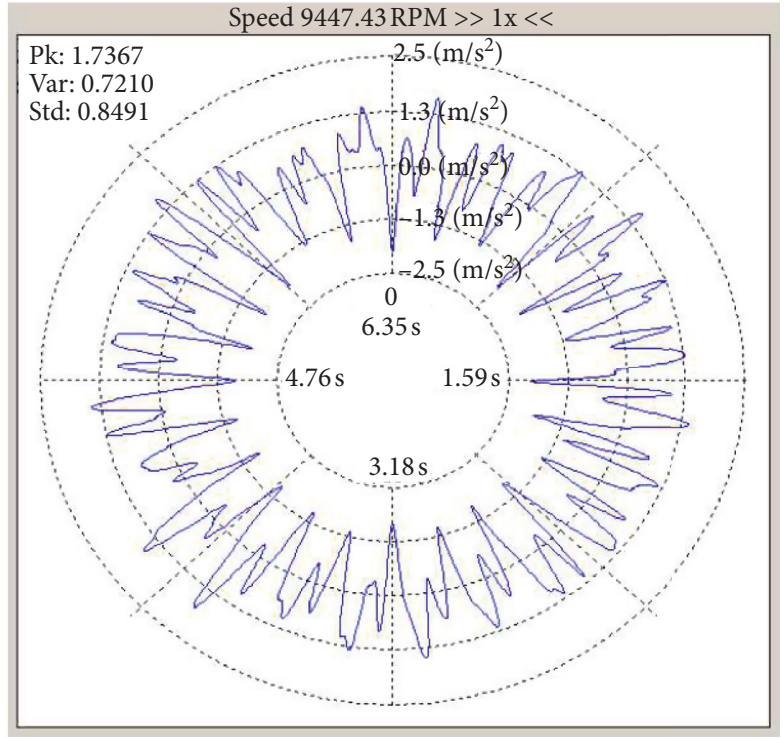

(b)

FIgURE 5: CTA analysis, quiet and unstable operation of the gear unit.

TABLE 1: Assessment of kinematic viscosity and water content in lubricants.

\begin{tabular}{lll}
\hline & \multicolumn{2}{c}{ Lubricant type } \\
& TG3 & TG4 \\
\hline Kinematic viscosity at $40^{\circ} \mathrm{C}\left(\mathrm{mm}^{2} / \mathrm{s}\right)$ & 48.2 & 45.4 \\
Water content $(\mathrm{mg} / \mathrm{kg})$ & 300 & 230 \\
\hline
\end{tabular}

TABLE 2: Concentration of additives in lubricants.

\begin{tabular}{lll}
\hline \multirow{2}{*}{ Concentration of additives (XRF) } & \multicolumn{2}{c}{ Lubricant type } \\
& TG3 & TG4 \\
\hline Phosphorus (\% w/v) & 0.13 & 0.06 \\
Sulphur (\% w/v) & 0.30 & 0.17 \\
\hline
\end{tabular}

TABLE 3: Reichert test.

\begin{tabular}{lcc}
\hline Reichert test & \multicolumn{2}{c}{ Lubricant } \\
type \\
$1.5 \mathrm{~kg}$, steel, track $100 \mathrm{~m}$, speed $1.7 \mathrm{~m} / \mathrm{s}$ & TG3 & TG4 \\
\hline Abrasive wear $\left(\mathrm{mm}^{2}\right)$ & 31 & 41 \\
Abrasive-wear-conditioned weight loss $(\mathrm{mg})$ & 67 & 104 \\
\hline
\end{tabular}

due to the formation of a lubricating film between the surfaces. This change is a result of the contact geometry progressing from a point contact to an area contact. The rated parameters of this test are the load bearing capacity of the lubricant film and the abrasive wear [16].

Table 3 shows a significant difference in lubricating properties again in the favor of TG3. The result is in line with the chemical analysis of the lubricant additives.

4.6. Comparison of FTIR Spectroscopy. FTIR stands for Fourier-transform infrared, the preferred method of infrared spectroscopy. Comparison of the FTIR spectra in Figure 6 is in the area of about $1000 \mathrm{~cm}^{-1}$ and shows the difference in oil filling TG3 relative to TG4 in terms of lubricant additives.

In the assessed spectrum, the P-O-C linkage signal is different, confirming the different chemical compositions and the different additive technologies for TG3 (blue) and TG4 (red) oil fillings:

Oil sample analysis and comparison of additives consumption from the TG3 gear unit in Figure 7 are shown as follows:

(i) Draught oil, new, unused (marked in blue) (Esso Teresstic EP46)

(ii) Oil removed from the TG3 gear unit, used (marked in red)

The FTIR spectrum shows a decrease in concentration and consumption of additives in the area of about $1000 \mathrm{~cm}^{-1}$. It is a mechanism of gradual decrease of additive elements in the real operation of contact surfaces (gear teeth engagement). When assessing the rate of element loss, trend analysis shows the following:

(i) Difficulty of gearing operation in terms of friction mode

(ii) The "quality" level of the oil filling and the microgeometry of the side of the toothing

\section{The Evaluation of Results of the Applied Measurements and Analyses: Discussion}

The turbo-generator unit with the gear unit transmits a power of $50 \mathrm{MW}$. Industrial practice shows several deficiencies that occur during the operation of machines in such an assembly. All deficiencies have a direct effect on the 


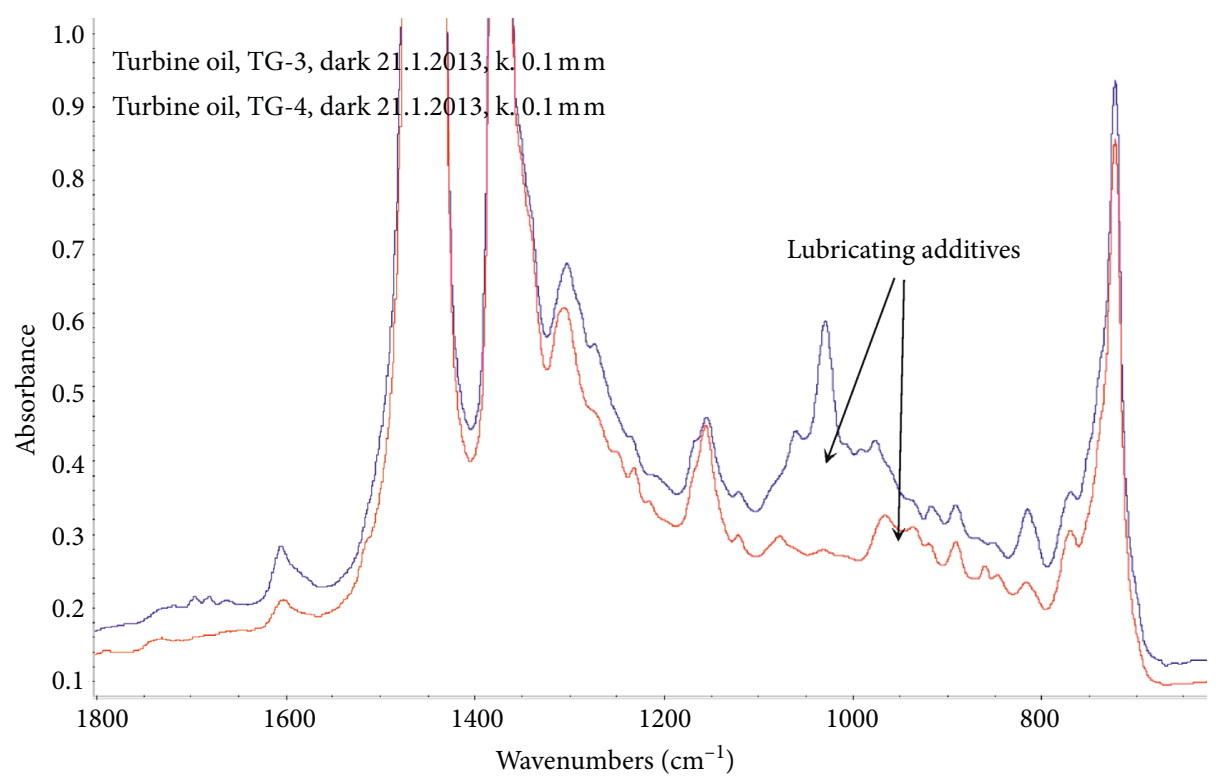

FIgURE 6: Comparison of the FTIR Spectra in terms of lubricant additives.

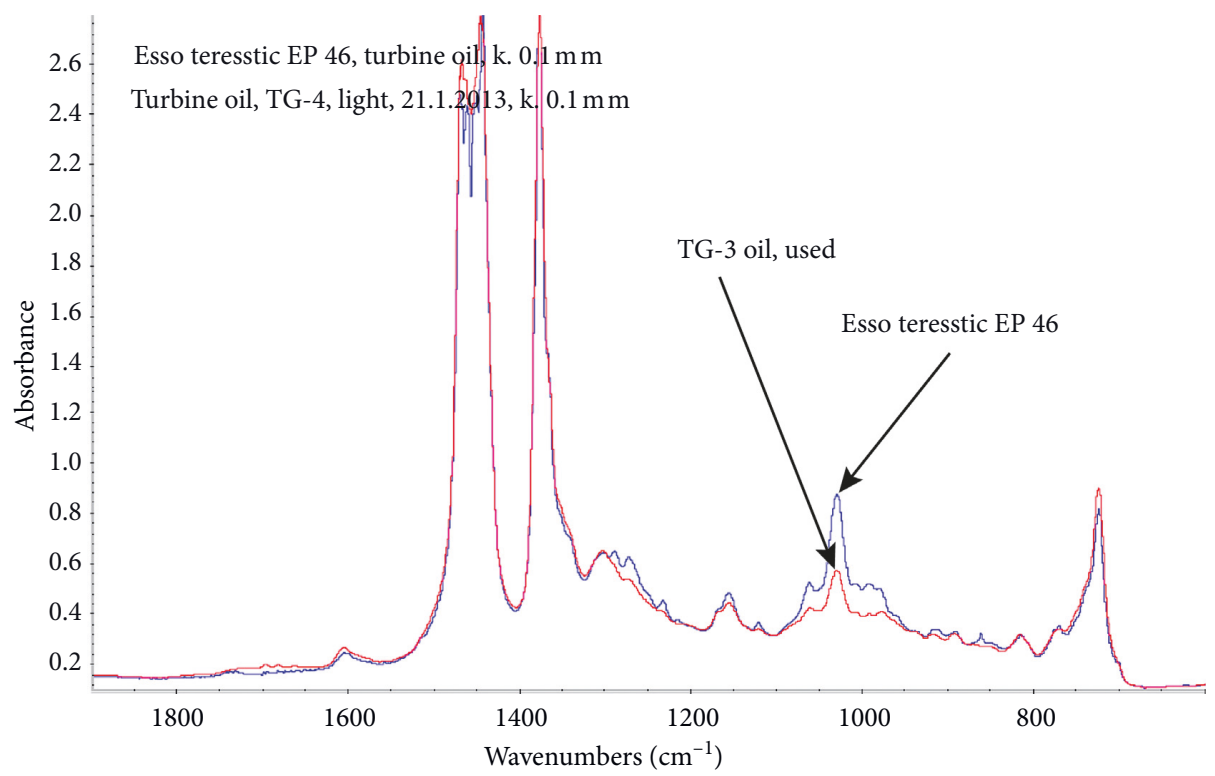

FIGURE 7: Comparison of FTIR spectra in terms of consumption of additives in the TG3 gear unit.

significant reduction in service life and/or reliability of machine operation. This paper describes and approaches the techniques of technical diagnostics that have been applied in our research. The first step was the online monitoring of high-frequency absolute vibrations during 24-hour operation of the turbo generator. The next step was the frequency analysis of the signal in the high-frequency area where the dynamic signal area was also displayed in the high-frequency area of the absolute vibrations using the frequency spectra. Subsequently, a CTA analysis was performed to show the gear teeth engagement. After this analysis, it was shown that the gear teeth engagement during instability was significantly impaired, resulting in changes in toothing surfaces and microgeometry. This causes early toothing failure due to its subsequent damage. The final step was to assess the condition of two different lubricants. Kinematic viscosity, water content, additive concentration, Reichert test, and FTIR spectrum were examined.

The analyzes performed confirmed the assumption of a significant correlation between the measured dynamic parameters and the friction mode. The tests show a relatively strong correlation of the high-frequency vibrational signal of absolute vibrations on the frequency of gear teeth engagement, amplitude increase well above the recommended limit (Alarm2-Danger), with inappropriate gear teeth engagement (the slew/slip ratio shown in the CTA analysis). Furthermore, we examined friction mode and lubricant condition, additive element concentration with respect to EP 
and WP lubricant properties, and carried out the trend analysis on oil lubricant properties. In order to avoid this adverse effect in the future, it is necessary to perform regular monitoring of these selected parameters and to examine the physical/chemical properties of the lubricant, with an emphasis on EP and WP oil properties. In addition, it is advisable to optimize and choose the oil filling with regard to the design of the machine, the operating conditions of the gear unit, the presence of water, the thermal dilatations, the relative speed of the contact surfaces, and the transmitted power (contact pressures with respect to microgeometry wear).

\section{Conclusion}

In technical practice, vibrodiagnostics plays an irreplaceable role in assessing the current state of technical systems. The basis is the analysis of the vibration signal, which represents information about the current operating condition, or about changes that occurred during the operation of the system under examination. By applying vibrodiagnostic tools, it is possible to identify the following unwanted machine and equipment states:

(i) Imbalance

(ii) Shafts-couplings misalignment

(iii) Bearing defects and wear

(iv) Rotor eccentricity

(v) Mechanical loosening

(vi) Bending of the shaft

(vii) Errors in structures

(viii) Gearbox failures

Based on the categorization of cog gear transmission defects, it is possible to identify the relevant malfunctions: damage due to fatigue (contact fatigue and fatigue breakage of the cog), damage caused by other factors (abrasive wear of cog surfaces by particles in the lubrication system, adhesion wear-formation of microscopic welds, and subsequent breakage), permanent deformations, run-out, and progressive pitting [17]. When the cogs engage, they roll away and slide. Such rolling and sliding motion has a significant effect on the lateral cog surface wear [18]. Operating conditions that considerably determine the extent and type of damage are the magnitude of the border cog load, the peripheral speed of rotation, and the quality and properties of the lubricant applied. A nonnegligible role in the possible damage to gearbox cogs plays the manner and the nature of installation of the technical system. Axial misalignment of the driving and the driven shaft generates dynamic forces that contribute to the wear of bearings, shafts, and cogwheels [19].

This paper describes the application of vibrodiagnostic and tribodiagnostic instruments in assessing the operating status of the gearbox in the technical system of a turbo generator. The manifestations of impaired gearbox cog engagement were recorded by high-frequency vibration analysis on the turbo-generator gearbox marked by the TG4 symbol. In case of the said gearbox, the friction mode and oil condition as well as the additive concentration with respect to EP and WP properties of the lubricant and the trend analysis of the elements determining the lubricating properties of the oil were then assessed. The results were compared with the results of the TG3-marked oil filling analyses. In both cases, turbine oil with different concentrations of EP and WP additives was applied. The analysis and the subsequent comparison of the chemical and physical properties confirmed operational problems in case of the gearbox identified as TG4.

The study has confirmed the existence of a correlation between the monitored dynamic parameters and the current friction mode. From the vibration spectra analyses, increased levels of the cog engagement component and their harmonic multiples are visible. Analysis of profile charts indicates a significant deformation at the output from the gearbox from transverse force. One of the causes may be an inappropriate installation of the clutch between the gearbox and the generator. The graph also shows insufficient smoothness of the cog engagement.

Continuous checking of the lubricant level in rotary machines is important for maintaining high reliability of the technical system. Suitable lubricant selection may significantly extend the service life. In addition, it is necessary to take into account all the important circumstances and assumptions and to include those considerations in the final application.

Applied measurements and analyzes have confirmed important information for practice, namely, the existence of a direct link between the level of dynamic parameters assessed in the form of high-frequency vibrations and acoustic emission and the real state of lubrication of the gearing contact surfaces. The purpose of lubrication is to minimize friction, to dissipate the heat generated by friction, and, of course, to reduce wear on the tooth teeth of the gears [20]. The geometrical shape of the flanks of the teeth determines the rolling and sliding movements so that the gears often work in the mixed friction area. This is confirmed by the types of possible gearbox damage and measurable power losses [21].

The research has led to a recommendation given to the turbo-generator system operator on how to optimize the oil filling and how to select the right one with regard to the machine design, gearbox operating conditions, presence of water, transmission performance, and so on.

Based on the conducted measurements and analyzes, it can be stated that the physical and chemical stabilities of the lubricant significantly affect the reliable operation of the friction nodes of the technical systems. Lubricant degradation can be caused by various influences including increased operating temperature, mixing of lubricants, moist or dusty environment, oxidation, loss of additives, increased impurity ratio, and so on. Lubricating oil additives determine the EP and WP lubricity properties of the oils in service, especially at high speed and contact pressure at the oil film site, which is the case of gear transmission. The purpose of adding additives to the lubricant is to improve its performance properties, such as separation from air or water 
and also to suppress unwanted phenomena (tendency to paraffin formation at low operating temperatures). However, over time, the additives are lost, their volume is reduced, and the lubricant's operating properties must be restored.

The loss of additives depends on the type of additives as well as the operating conditions, partly on the temperature and the presence of water. Some additives condense and separate from the base oil at low temperatures. Many additives are sensitive to hydrolysis, and the presence of water in the lubricant often damages the additive system. Continuous checking of lubricant condition and life is one of the most important activities related to the application of proactive maintenance methods [21].

\section{Data Availability}

The data used to support the findings of this study are included within the article.

\section{Conflicts of Interest}

The authors declare that they have no conflicts of interest.

\section{Acknowledgments}

The authors thank the Ministry of Education of Slovak Republic for supporting this research by the grant KEGA 001TUKE-4/2018 (Implementation of concurrent engineering philosophy to educational tool in the field of computer-aided technological preparation) and Slovak Research and Development Agency under the contract no. APVV-16-0355.

\section{References}

[1] R. Kumar, S. Chatopadhyaya, S. Hloch, G. Krolczyk, and S. Legutko, "Wear characteristics and defects analysis of friction stir welded joint of aluminum alloy 6061-T6," Eksploatacja I Niezawodnosc-Maintenance and Reliability, vol. 18, no. 1, pp. 128-135, 2016.

[2] G. Krolczyk, S. Legutko, and A. Stoic, "Influence of the cutting parameters and conditions onto surface hardness of duplex stainless steel after turning," Tehnicki Vjesnik-Technical Gazette, vol. 20, no. 6, pp. 1077-1080, 2013.

[3] S. Legutko, "Development trends in machines operation maintenance," Eksploatacja I Niezawodnosc-Maintenance and Reliability, vol. 2, no. 42, pp. 8-16, 2009.

[4] K. Lu, L. He, and Y. Zhang, "Experimental study on vibration reduction characteristics of gear shafts based on ISFD installation position," Shock and Vibration, vol. 2017, Article ID 7246356, 10 pages, 2017.

[5] R. Fargère and P. Velex, "Some experimental and simulation results on the dynamic behaviour of spur and helical geared transmissions with journal bearings," Advances in Tribology, vol. 2012, Article ID 163575, 9 pages, 2012.

[6] R. Bajric, N. Zuber, G. A. Skrimpas, and N. Mijatovic, "Feature extraction using discrete wavelet transform for gear fault diagnosis of wind turbine gearbox," Shock and Vibration, vol. 2016, Article ID 6748469, 10 pages, 2016.

[7] N. Barbieri, G. de Sant'Anna Vitor Barbieri, B. M. Martins, L. de Sant'Anna Vitor Barbieri, and K. F. de Lima, "Analysis of automotive gearbox faults using vibration signal," Mechanical Systems and Signal Processing, vol. 129, pp. 148-163, 2019.

[8] Z. Chen, C. Li, and R.-V. Sanchez, "Gearbox fault identification and classification with convolutional neural networks," Shock and Vibration, vol. 2015, Article ID 390134, 10 pages, 2015.

[9] M. Strączkiewicz and T. Barszcz, "Application of artificial neural network for damage detection in planetary gearbox of wind turbine," Shock and Vibration, vol. 2016, Article ID 4086324, 12 pages, 2016.

[10] N. K. Myshkin and L. V. Marková, "Trends in on-line tribodiagnostics," in On-Line Condition Monitoring in Industrial Lubrication and Tribology, pp. 203-223, Springer, Cham, Switzerland, 2018.

[11] A. Glowacz, W. Glowacz, Z. Glowacz, and J. Kozik, "Early fault diagnosis of bearing and stator faults of the single-phase induction motor using acoustic signals," Measurement, vol. 113, pp. 1-9, 2018.

[12] J. Furch, J. Glos, and T. T. Nguyen, "Identification of the technical condition of roller bearings by means of vibrodiagnostics and tribodiagnostics," Transactions of FAMENA, vol. 41, no. 3, pp. 99-113, 2017.

[13] J. Glos, "Tribologic methods used for an engine diagnostic," in Proceedings of the Intelligent Technologies in Logistics and Mechatronics Systems (ITELMS 2011), pp. 9-13, Panevėžys, Lithuania, May 2011.

[14] E. M. Portnov, K. Z. Lin, V. V. Kokin, and A. K. Myo, "Method for detection of failures in complex process control systems," in Proceedings of the 2017 IVth International Conference on Engineering and Telecommunication (EnT), pp. 145-149, IEEE, Moscow, Russia, November 2017.

[15] P. Jayaswal, A. K. Wadhwani, and K. B. Mulchandani, "Machine fault signature analysis," International Journal of Rotating Machinery, vol. 2008, Article ID 583982, 10 pages, 2008.

[16] M. Batsch, T. Markowski, S. Legutko, and G. M. Krolczyk, "Measurement and mathematical model of convexo-concave Novikov gear mesh," Measurement, vol. 125, pp. 516-525, 2018.

[17] I. Kuric, M. Cisar, T. Novosad et al., "Experimental device for practicing routines of machine tool precision measurement," Academic Journal of Manufacturing Engineering, vol. 13, no. 1, pp. 39-44, 2015.

[18] G. M. Krolczyk, J. B. Krolczyk, S. Legutko, and A. Hunjet, "Effect of the disc processing technology on the vibration level of the chipper during operations process," Technical Gazette, vol. 21, no. 2, pp. 447-450, 2014.

[19] I. Vojtko, P. Baron, M. Pollák, and J. Kaščak, "Examining the effect of alignment of the rotor of the emissions exhaust fan on its operating parameters," Advances in Materials Science and Engineering, vol. 2019, Article ID 4985395, 13 pages, 2019.

[20] R. W. Maruda, E. Feldshtein, S. Legutko, and G. M. Krolczyk, "Analysis of contact phenomena and heat exchange in the cutting zone under minimum quantity cooling lubrication conditions," Arabian Journal for Science and Engineering, vol. 41, no. 2, pp. 661-668, 2016.

[21] P. Dálik, "Diagnostika hydraulických olejov," Tribotechnika, vol. 4, pp. 18-19, 2011. 


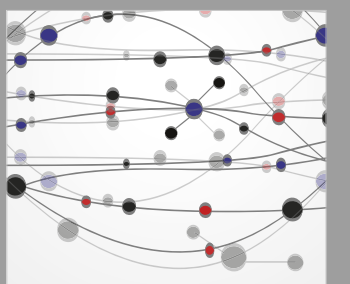

The Scientific World Journal
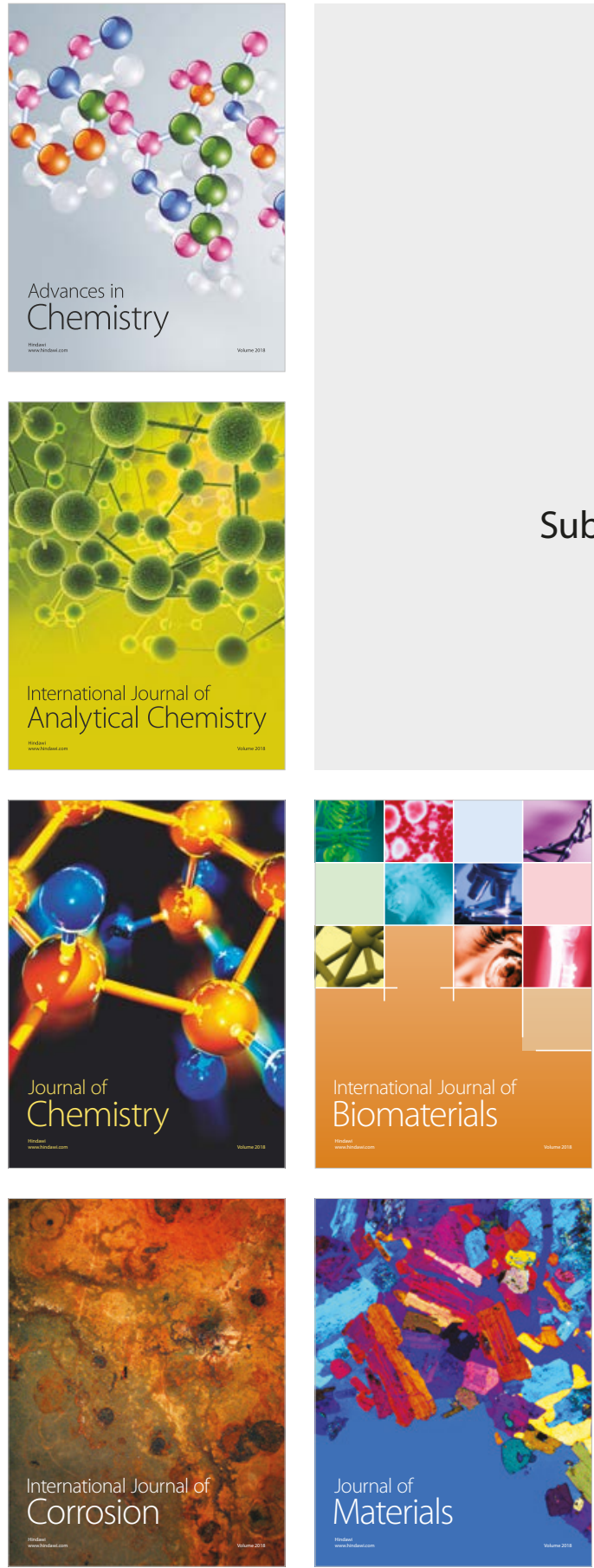

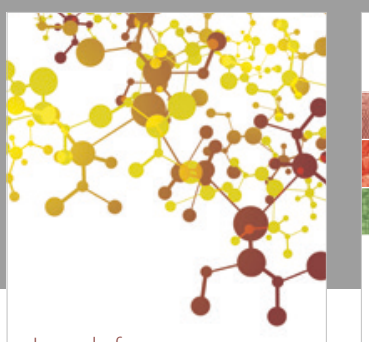

Journal of

Applied Chemistry
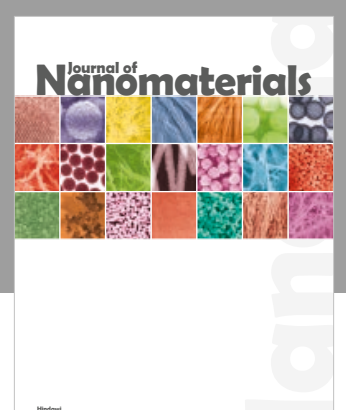

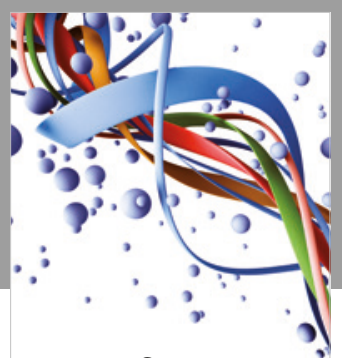

Scientifica

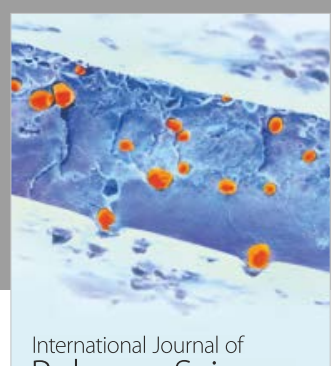

Polymer Science

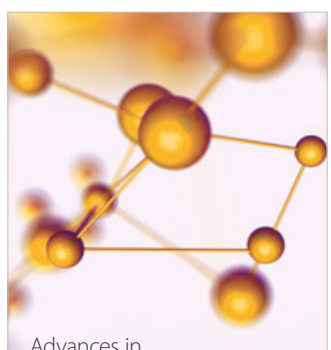

Physical Chemistry
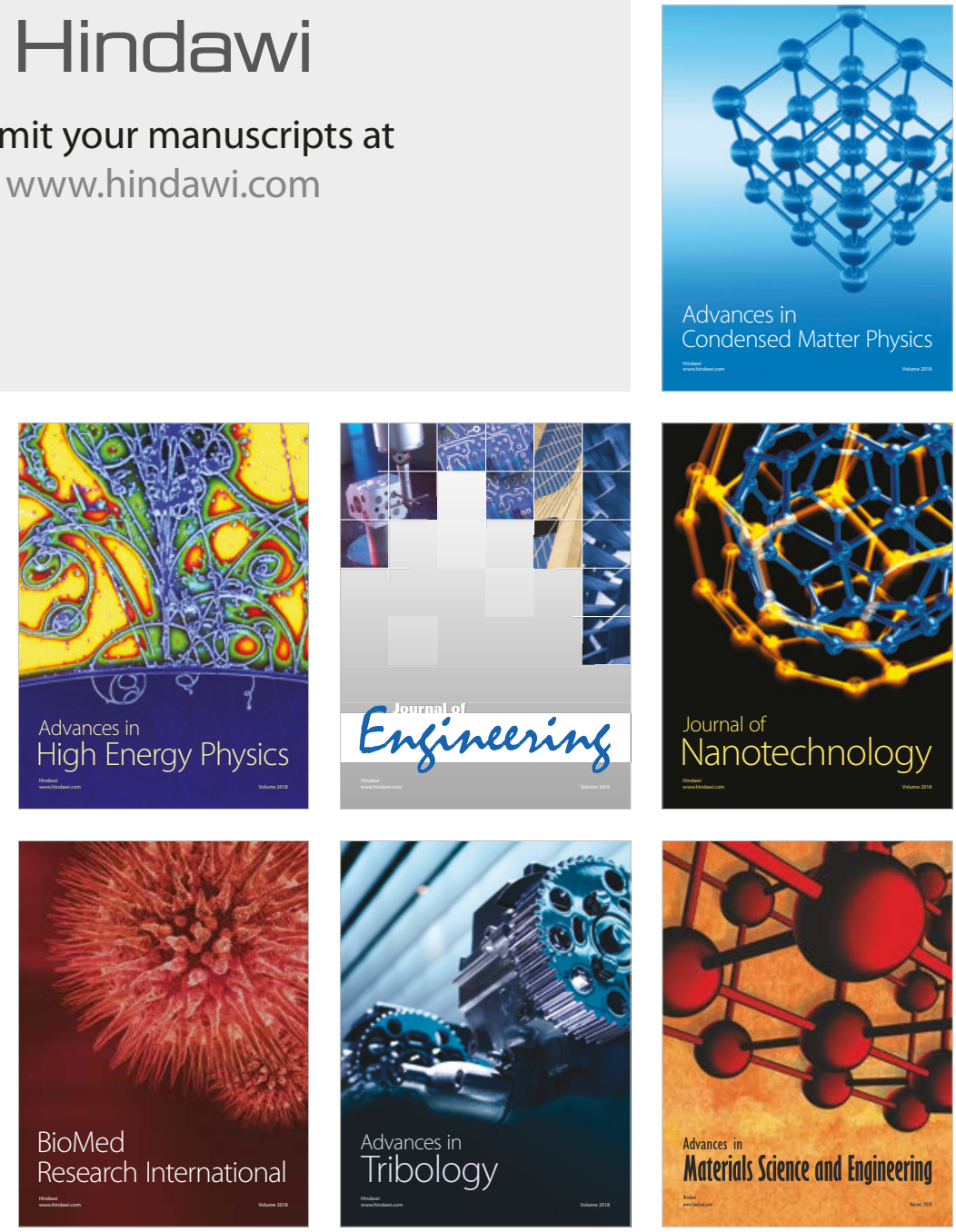